\title{
Patients' satisfaction with ophthalmic counselling services in a tertiary hospital in Calabar, South-South Nigeria.
}

\author{
Bassey A. Etim ${ }^{1}$, Affiong A. Ibanga ${ }^{1}$, Martha-Mary E. Udoh ${ }^{2}$, Elizabeth D. Nkanga ${ }^{1}$, Utam A. \\ $\mathrm{Utam}^{2}$ and John A. Okwejie ${ }^{2}$
}

Ghana Med J 2020; 54(2): 76-81 DOI: http://dx.doi.org/10.4314/gmj.v54i2.4

\author{
${ }^{1}$ Department of Ophthalmology, University of Calabar and University of Calabar Teaching Hospital, Calabar, \\ Nigeria. \\ ${ }^{2}$ Department of Ophthalmology, University of Calabar Teaching Hospital, Calabar, Nigeria
}

Corresponding author: Bassey A. Etim

Email: baseti2002@yahoo.com

Conflict of interest: None declared

\section{SUMMARY}

Objective: To assess the level of satisfaction of patients who access the Ophthalmic counselling services anchored by trained social workers of the University of Calabar Teaching Hospital, Calabar, Nigeria

Methods: A cross-sectional study of serial consenting participants was done. Ethical approval was obtained from the University of Calabar Teaching hospitals' ethics committee. Data was obtained using a semi-structured intervieweradministered questionnaire. Data were collated and analyzed using the SPSS for Windows (version 20, SPSS inc. Chicago, IL, USA). Modified Likert scale (very satisfied, satisfied and not satisfied) was used to rate the satisfaction level.

Results: A total of 120 respondents met the inclusion criteria and were enrolled into the study. Majority of the respondents $(60 \%)$ were male with an overall mean age of $45.32 \pm 1.82$. Over a quarter $(28.3 \%)$ of the respondents were in the age bracket of 41-50. Glaucoma (48.3\%) was the most common eye condition of the respondents. Seventy-five percent of the respondents were satisfied with the average time spent for the counselling services while $76.7 \%$ were satisfied with the overall ophthalmic counselling services they received with $46.7 \%$ believing that the service was provided by a social worker.

Conclusion: Majority of the Patients were satisfied with the Ophthalmic counselling services mainly anchored by social workers. Training and retraining of allied support staff to render ophthalmic counselling services in order to ease the workload of the Ophthalmologist should be encouraged in resource-limited settings.

Keywords: Patients satisfaction, ophthalmic counselling service, Nigeria Funding: None declared

\section{INTRODUCTION}

Patients counselling is gradually taking a front line in holistic health care management in most health care facilities throughout the world. Patients counselling services are instituted to engage patients so that they can understand disease conditions, disease management, health behaviour change, as well as guide them in making decision with regards to various treatment options available. ${ }^{1} \mathrm{~Pa}-$ tients counseling may be regarded as a talking-based therapy by a trained therapist. ${ }^{2}$ Providing counseling services is extra burden and time-consuming for treating physicians due to increased workload and lack of training in communication. Despite the time consuming effect associated with counselling, it is believed that with good counselling, fears about disease conditions are reduced with an accompanying level of satisfaction and comfort

on leaving the care giver. ${ }^{2}$ In the past, counselling in hospital settings was mainly done by doctors and nurses who cared for the patients. In recent times, due to increasing workload of doctors and nurses, counselling services are now being provided by trained non-clinical staff in some health facilities because patients counselling is a lengthy cooperative mode of work demanding active participation from both practitioner and client. ${ }^{3}$

Hospital based patients counselling services seems to be more grounded and more applied in psychiatric services probably due to the peculiarities of psychiatric specialty. ${ }^{4}$ Over the years, there has also been a sustained increase and strengthening of patient education and counselling services in conditions like cancers and HIV/AIDS. ${ }^{5,6}$ 


\section{Original Article}

Other medical services like nursing services routinely incorporate patient communication, education and counselling services in their daily clinical activities to help improve overall patient wellbeing as they pass through various stages of management. ${ }^{7}$ The trend therefore in patient counselling services, is the movement from general patient counselling services to specific disease counselling services. For this trend to be fully realised, patients counselling units or departments needs to be established in all the specialties in our health facilities and a simple patients satisfaction survey will be a good tool for assessing the services rendered.

Several studies have shown that patients satisfaction survey is a veritable tool for measuring the quality of health care services. ${ }^{8-12}$ It is a very important component of a 360 degrees evaluation of services rendered in any health facility. Levels of satisfaction has a wide range which may be influenced by individual's expectations or desire. The expectations may be based on their experiences with care providers, environment, social background, peer group, personality, and cultural or religious beliefs. ${ }^{9}, 12 \mathrm{~A}$ combination of patients experiences, their satisfaction level with services rendered, and health service providers' self-assessment may be a handy, quick and cheap evaluation tool for health care services in a resource limited setting.

Patients satisfaction levels with eye care services using measuring factors as waiting time, availability of drugs and optical services, staff behaviour, availability of equipment, infrastructural convenience, surgical care and follow up visit engagements have been well documented. ${ }^{9,12-15}$ Furthermore, several studies have also documented patients experiences and satisfaction levels on specific ophthalmic disease condition services or specific eye care services as a component of the general eye care services. ${ }^{16-20}$ In spite of the vamoose literature on patients' level of satisfaction concerning general and specific eyecare services, no study to the best of our knowledge has specifically evaluated patient satisfaction levels with ophthalmic counselling services operated by trained clinical, non-clinical or paramedical support staff. This is probably because, ophthalmic counselling specialty is still developing, and ophthalmic counselling units are not common features in most hospitals that provide eye care services.

This study is aimed at assessing the satisfaction levels of patients who access the Ophthalmic counselling services of University of Calabar Teaching Hospital (UCTH).

The study also evaluates the task-shifting initiative in terms of effectiveness and suitability of trained non-clinical staff in providing ophthalmic counselling services at the UCTH, Calabar, Nigeria.

\section{METHODS}

A cross-sectional study of consecutive consenting participants referred to the counselling unit of the eye clinic of the department of ophthalmology, University of Calabar Teaching hospital (UCTH), Calabar, between January 2016 when it became fully operational and December 2018 was done. The data were obtained over a 3-month period from February to April 2019. Ethical approval (Reference number UCTH/HREC/33/286) for study was obtained from the Health Research Ethics Committee of the University of Calabar Teaching Hospital, Calabar, Nigeria. Permission to carry out the study in the Ophthalmology counselling unit was obtained from the Head of Department of Ophthalmology. Written informed consents were obtained from all consenting participants.

The ophthalmic counselling unit of eye clinic, UCTH is housed in a dedicated room within the department of ophthalmology. The room is designed for patients' confidentiality and is centrally located within the clinic for easy accessibility by patients. Patients who require longer period of counselling are referred to the counselling unit to help shorten clinic time. An average of 6 patients are counselled per week. The counselling sessions are individualized and at least 1 trained social worker counsellor renders counselling service per day.

All registered adult patients who had earlier accessed the services of the counselling unit were eligible to participate in the study. Those who gave consent were included in the study and were interviewed. Those excluded from the study were patients that were too ill to participate in interview, non-consenting patients, and patients younger than 18 years. The counselling unit patients' register with phone numbers was used in recruiting old patients who had gone through counselling session in the past 2 years via phone calls into the study. Those who consented via phone calls were requested to come to the eye clinic and complete a questionnaire. New patients seen during the 3 months period in the counselling unit were interviewed by a trained research assistant immediately after the counselling session in a different room. All participants in this study were interviewed in one of the screening rooms in the eye clinic to ensure confidentiality.

Data was obtained using a semi-structured intervieweradministered questionnaire. The domains in the questionnaire which was pretested and validated included; demographic data, type of eye disease, time spent in counselling unit, how participants felt after counselling, participant general satisfaction after counselling(understand disease condition better, attitude of the counsellor, confidentiality and environmental comfort), thoughts of who rendered the counselling service, and participants' willingness to repeat the counselling session. 
Satisfaction level was graded using a 3-piont modified Likert scale satisfaction rate. The satisfaction level responses were ranked as very satisfied, satisfied and not satisfied.

Using tables for the determination of sample size in Likert scale related analysis with a relative maximal tolerable error range of 5 to $10 \%$ and a 3-point item, the extracted sample size range from the table was 61 to 241 with coefficient of variation (c) $=0.5$ and pairwise correlation coefficient $(\mathrm{p})=0.5$ set as recommended parameters. ${ }^{21}$ At the end of the 3 months data collection period, 120 participants were recruited into the study.

Data from questionnaires were pre-coded and entered into Microsoft Excel 2010 and transferred to SPSS (Statistical Package for Social Sciences version 20, SPSS inc. Chicago, IL, USA software) for analysis. Categorical variables were presented as frequencies and percentages while continuous variables as means.

\section{RESULTS}

\section{Sociodemographic characteristics.}

One hundred and twenty (120) of all the eligible registered patients in counselling unit for the periods of study consented and participated in the study. Over $1 / 4$ th of the respondents 34(28.35) were aged 41-50 with the mean age of $45.32 \pm 1.82$ years and age range of 18-79 (Table 1). Majority of the respondents were males $72(60 \%)$. About 4(3.3\%) had no formal education while the rest had some form of education with those who had tertiary education 58(48.3\%) constituting most of the respondents. Only $5 \%$ of the respondents were unemployed. Other socio-demographic characteristics are as shown in Table 1.

\section{Presenting eye disorders of respondents who accessed counselling services.}

Table 2 shows distribution of disorders of participants. Glaucoma 58(48.3\%) was the most common eye condition of the respondents followed by cataract $32(26.7 \%)$. The other eye disorders of respondents are shown in Table 2 .

\section{Participants satisfaction with time spent and overall counselling services received \\ Using the modified Likert scale rating, 90(75\%) of the respondents were basically satisfied with the time spent for the counselling services and a further $8.3 \%$ were very satisfied. The remaining 20(16.7\%) were not satisfied.}

For the overall counselling services received, 92(76.7) and $16(13.3 \%)$ were satisfied and very satisfied respectively. Only $10 \%$ of the respondents were not satisfied with the overall counselling services received.
Table 1 Socio-demographics of study participants

\begin{tabular}{|c|c|c|}
\hline Variable & & Frequency $(\%)$ \\
\hline \multicolumn{3}{|l|}{ Gender } \\
\hline & Males & $72(60)$ \\
\hline & Females & $48(40)$ \\
\hline \multicolumn{3}{|l|}{ Age group(years) } \\
\hline & 10 to 20 & $6(5.0)$ \\
\hline & 21 to 30 & $16(13.3)$ \\
\hline & 31 to 40 & $14(11.7)$ \\
\hline & 41 to 50 & $34(28.3)$ \\
\hline & 51 to 60 & $16(13.3)$ \\
\hline & 61 to 70 & $20(16.7)$ \\
\hline & 71 to 80 & $14(11.7)$ \\
\hline Overall Mean age & $45.32 \pm 1.82$ & \\
\hline Mean age(male) & $44.28 \pm 1.91$ & \\
\hline Mean age (female) & $46.39 \pm 1.73$ & \\
\hline Range & $18-79$ & \\
\hline \multicolumn{3}{|l|}{ Educational Status } \\
\hline & None & $4(3.3)$ \\
\hline & Primary & $16(13.3)$ \\
\hline & Secondary & $28(20.0)$ \\
\hline & Tertiary & $72(60.0)$ \\
\hline \multicolumn{3}{|l|}{ Tribe } \\
\hline & Efik & $18(15.0)$ \\
\hline & Ibibio & $24(20.0)$ \\
\hline & Ekoi & $16(13.3)$ \\
\hline & Igbo & $14(11.7)$ \\
\hline & Annang & $14(11.7)$ \\
\hline & Hausa & $13(10.8)$ \\
\hline & Yoruba & $13(10.8)$ \\
\hline & Others & $8(6.7)$ \\
\hline \multicolumn{3}{|l|}{ Employment Status } \\
\hline & Public servant & $38(31.7)$ \\
\hline & $\begin{array}{l}\text { Private sector } \\
\text { worker }\end{array}$ & $10(8.3)$ \\
\hline & Self-employed & $40(33.3)$ \\
\hline & Retiree & $10(8.3)$ \\
\hline & Student & $16(13.3)$ \\
\hline & Unemployed & $6(5.0)$ \\
\hline
\end{tabular}

Table 2 Distribution of eye conditions of participants

\begin{tabular}{|l|l|}
\hline Eye disorders & $\mathbf{N}(\%)$ \\
\hline Glaucoma & $58(48.3)$ \\
\hline Cataract & $32(26.7)$ \\
\hline High refractive error & $6(5.0)$ \\
\hline Retinal conditions & $4(3.3)$ \\
\hline Removal of the eye & $6(5.0)$ \\
\hline Others & $14(11.7)$ \\
\hline Total & $120(100)$ \\
\hline
\end{tabular}

Participants' thoughts on who rendered the counselling service

Social worker counsellors $56(46.7 \%)$ followed by eye doctors $40(33.3 \%)$ were the cadre of staff thought by respondents to have handled the counselling session. About $13 \%$ of the respondents felt the counselling session was anchored by a nurse.

\section{Willingness to repeat counselling services and choice of counsellors}

Ninety (75\%) of the respondents did not raise any objection to repeating the ophthalmic counselling session. 


\section{Original Article}

For those who were willing to go through the counselling services again, $39(43.3 \%), 28(31.1 \%)$ and $20(22.2 \%)$ said they will prefer a social worker counsellor, doctor and nurse respectively to handle their ophthalmic counselling sessions.

\section{DISCUSSION}

New and old health care services can be evaluated using patients' satisfaction tool and this is a subjective measure which depends on the patients' preference and perceived expectation. ${ }^{10,13,22,23}$ The result of this study is an evaluation of an added service unit, the ophthalmic counselling unit of UCTH.

The demographics of respondents in this study is not significantly different from other studies on patient satisfaction of health care services even though they were not specifically done for ophthalmic counselling services. ${ }^{9,11,14,18}$ The high level of patients' satisfaction with time spent (75\%) and overall services received (76.7\%) indicates that the ophthalmic counselling services met the respondents' needs and expectations. Taking into consideration the very satisfied group, this study shows that over $80 \%$ and about $90 \%$ were satisfied with time spent and overall counselling service received respectively. The high satisfaction with waiting time may have been as a result of few patients scheduled for counselling each day. Another reason may have been due to the dedication and respect for time by the ophthalmic counsellor service providers. Studies have linked less waiting time to a direct effect on overall patients' satisfaction of health care services. ${ }^{924,25}$ Long waiting time is directly related to patients' dissatisfaction while short waiting time is linked to good patients' satisfaction with services.

The high level of satisfaction on the overall ophthalmic counselling services received by the respondents may be attributed to the fact that the counsellors were trained and retrained on various hospital-client related issues to enable them to provide satisfactory services to the patients. The counsellors received trainings on hospitality, clientservice provider relationship and communications, prevalent ophthalmic disease conditions referred to the counselling unit as well as patients' comfort and confidentiality. The high level of patient satisfaction with ophthalmic counselling services in this study is comparable to high satisfaction level recorded on different studies concerning general eye care services in Nigeria ${ }^{12,26}$ and Brazil2 ${ }^{27}$

General health care services including eye care services in sub-Saharan Africa are gradually embracing the taskshifting initiative for effective service delivery due to increase workload for clinical staff and shortage of physi$\operatorname{cian}^{28,29}$
To this end, support staff are trained to effectively carry out task that were initially designated in the domain of physicians..$^{28}$ In our study, social workers were trained to provide ophthalmic counselling services to clients referred to the ophthalmic counselling unit. Almost half of the respondents who accessed the ophthalmic counselling service were able to identify their ophthalmic counsellor service provider as a social worker counsellor while a quarter of them thought the service providers were doctors. The reason for the thoughts of social worker counsellor as the service provider may have been due to the dressing pattern of the counsellors, the use of name tags, or due to room where the counselling service was carried out.

Even though half of the respondents identified service provider as a social worker counsellor, three quarter of them were happy and willing to repeat the counselling session with about $43 \%$ agreeing to see the social worker counsellor again. This was still higher than those who will want to see the doctor $(31.1 \%)$, nurse $(22.2 \%)$ and others (3.3\%) in their repeat ophthalmic counselling session.

The reason for the high percentage of respondents who were happy and willing to go through the counselling services again may be attributed to the level of satisfaction derived from the first counselling session. Furthermore, the fact that most of the respondents who agreed to a repeat counselling session preferred it done with the social worker counsellor further buttress the point that they were satisfied with the ophthalmic counselling service provider. This shows that a well-conceived and strategized task-shifting initiative involving non-clinical staff can be made an integral part of ophthalmic counselling service delivery in a resource limited economy characterized by shortage of physicians. Trained health support staff are important in task-shifting initiative for effective and timely ophthalmic service delivery in the area of ophthalmic counselling. Therefore, training and retraining of allied support staff to render ophthalmic counselling services in order to ease the workload of the Ophthalmologist and other clinical staff should be highly encouraged in resource-limited settings.

\section{Limitations:}

Some old patients did not have their phone numbers documented in the patients' register. For those who had their phone numbers in the patients' register, some of them could not be reached with the phone numbers they gave. Incessant power outage in the entire eye clinic during the period of study may have had some effects on the participants. 


\section{CONCLUSION}

In this study, majority of the respondents were satisfied with the Ophthalmic counselling services mainly anchored by trained social worker counsellors.

\section{ACKNOWLEDGEMENT}

We acknowledge the contributions of the social worker counsellors Mr Ikpeme, Mr Ofonime, Ms Theresa and Mr Bassey. We also acknowledge our research assistant, Mrs Offiong Okon who helped during and after the research.

\section{REFERENCES}

1. Krist AH, Tong ST, Aycock RA, Longo DR. Engaging patients in decision-making and behavior change to promote prevention. Information Services \& Use. 2017; 37: 105-22

2. Raju B, Reddy K. Are Counseling Services Necessary for the Surgical Patients and their Family Members during Hospitalization? J Neurosci Rural Pract. 2017;8(1):114-17.

3. Reddy K, Durai Pandi A, Ahemed A. Handbook of Psychiatric Social Work. 1st ed. Bangalore: National Institute of Mental Health and Neurosciences; 2007. Psychosocial interventions in neurosurgical setting; pp. 228-36.

4. Connolly A, O'Callaghan D, O'Brien O, Broderick J, Long C, O'Grady I. The development of counselling psychology in Ireland. Ir J Psychol. 2014;35(1):1624. doi:10.1080/03033910.2014.896270

5. Tran Y, Lamprell K, Nic Giolla Easpaig B, Arnolda $\mathrm{G}$, Braithwaite J. What information do patients want across their cancer journeys? A network analysis of cancer patients' information needs. Cancer Med. 2019;8(1):155-64

6. Chippindale S, French L. HIV counselling and the psychosocial management of patients with HIV or AIDS. BMJ 2001; $322: 1533$

7. Ledesma-Delgado E, Mendes MM. The nursing process presented as routine care actions: building its meaning in clinical nurses' perspective. Rev Lat Am Enfermagem. 2009; (3):328-34.

8. Umar I, Oche M O, Umar AS. Patient waiting time in a tertiary health institution in Northern Nigeria. Journal of Public Health and Epidemiology. 2011; 3(2) :78-82.

9. Ibanga AA, Nkanga DG, Asana UE, Duke RE, Etim BA, Nkanga ED, Utam UA, Agweye CT, Udofia OO. Patients' satisfaction with eye care services in University of Calabar Teaching Hospital. IAIM. 2017; 4(9): 110-18.

10. Ware J, Snyder M, Wright R. Defining and measuring patient satisfaction with medical care. Eval Prog Planning. 1983; 6: 247-63.
11. Ajayi I, Olumide E, Oyediran O. Patient satisfaction with the services provided at a general outpatient department clinic, University College Hospital Ibadan. Africa Journal of Medical Science. 2005; 34: 13340.

12. Ezegwui IR, Okoye OI, Aghaji AE, Okoye O, Oguego N. Patients' satisfaction with eye care services in a Nigerian teaching hospital. Nigerian Journal of Clinical Practice. 2014; 17(5): 585-8.

13. Alkhalaileh M, Hasan AA, Al-Kariri NS, Ibaid AA. Assessing Patients' Satisfaction with the Quality of Ophthalmic Services at Saint John Gaza Eye Clinic. American Journal of Public Health Research. 2017; 5(1): 15-22.

14. Sudhan A, Khandekar R, Deveragonda S, Devi S, Jain B K, Sachan R, Singh V. Patient satisfaction regarding eye care services at tertiary hospital of central India. Oman J Ophthalmol. 2011;4:73-76

15. Karn R, Singh DS. Patient satisfaction of eye care services at Biratnagar Eye Hospital, Nepal. International Journal of Perceptions in Public Health. 2018; 2(3):151-7.

16. Pui-Yan Au C, Fardell N, Williams M, Fraser-Bell $\mathrm{S}$, Campaign A, Gillies M. Patient experiences in retinal trials: a cross-sectional study. BMC Ophthalmology 2015;15:80. https://doi.org/10.1186/s12886015-0071-6. Accessed 21/07/2019

17. Lemij HG, Hoevenaars JG, van der Windt C, Baudouin C. Patient satisfaction with glaucoma therapy: reality or myth? Clin Ophthalmol. 2015;9:785-93. doi:10.2147/OPTH.S78918

18. Olawoye O, Ashaye A, Bekibele C, Ajuwon AJ. A comparative evaluation of patient's satisfaction with cataract surgical services in a public tertiary and a private secondary eye care facility in Nigeria. Ann Afr Med. 2012;11(3):157-62

19. Putterman AM. Patient satisfaction in oculoplastic surgery. Ophthalmic Surg. $1990 ; 21(1): 15-21$

20. Newman-Casey PA, Ravilla S, Haripriya A, et al. The Effect of Counseling on Cataract Patient Knowledge, Decisional Conflict, and Satisfaction. Ophthalmic Epidemiol. 2015;22(6):387-93.

21. Park J, Jong M. A note on determination of sample size for a Likert scale. Communications of the Korean statistical society. 2009; 16(4):669-73.

22. Rizyal A. Patients' satisfaction with eye care services at Nepal Medical College. Nepal Med Coll J. 2012; 14(3): 172-5.

23. Larson LN, Rovers JP, MacKeigan LD. Patient satisfaction with pharmaceutical care: update of a validated instrument. J Am Pharm Assoc. 2002; 42: 4450.

24. Nandkeshav AR, Kalpana KM, Mangesh RP, Akanksha J, Balaji BS. Patients waiting time and their satisfaction of health care services provided at 
outpatient department of Government Medical College, Nanded (Maharashtra, India). International $J$ Health Sciences \& Research. 2014; 4(4):21-27

25. Patel HR. A study on waiting time and out-patient satisfaction at Gujarat medical education research society hospital, Valsad, Gujarat, India. Int J Community Med Public Health. 2017;4: 857-63.

26. Megbelayin EO, Babalola YO, Kurawa MS, Opubiri I, Okonkwo SN. How satisfied are patients attending a Nigerian eye clinic in University of Calabar Teaching Hospital? International Archives of Integrated Medicine. 2014; 1(4): 1-9.
27. Oliveira D, Arieta C, Temporini E, KaraJosé N. Quality of health care: patient satisfaction in a university hospital. Arq Bras Oftalmol. 2006; 69(5): 731-6.

28. Ledikwe JH, Kejelepula M, Maupo K, et al. Evaluation of a well-established task-shifting initiative: the lay counselor cadre in Botswana. PLoS One. 2013;8(4):e61601. Published 2013 Apr 9. doi:10.1371/journal.pone.0061601

29. Gichangia M, Kaluabc K, Barassaa E, Eliahd E, Lewallende S, Courtrightde P. Task shifting for eye care in Eastern Africa: General nurses as trichiasis surgeons in Kenya, Malawi, and Tanzania. Ophthalmic Epidemiology. 2015;22(3):226-230. 